Dossiê: Ensino de História, História das Mulheres e Desigualdades Sociais no Brasil

\title{
DANDARA DOS PALMARES: UMA PROPOSTA PARA INTRODUZIR UMA HEROÍNA NEGRA NO AMBIENTE ESCOLAR
}

\section{DANDARA DOS PALMARES: A PROPOSAL TO PRESENT A BLACK HEROINE IN THE SCHOLAR ENVIRONMENT}

\author{
Janaína Oliveira Caetano ${ }^{1}$ \\ Helena Carla Castro ${ }^{2}$
}

\begin{abstract}
Resumo: Várias protagonistas negras, como Dandara dos Palmares, foram excluídas da História oficial do Brasil contada em nossas escolas, resultante não só do racismo, dentre vários fatores, mas também do machismo e do sexismo ainda existente em nossa sociedade. Como uma de suas consequências está a falta de identificação das meninas afrodescendentes com personagens femininas negras. Assim, este artigo tem por objetivo apresentar uma proposta de atividade pedagógica a partir da divulgação da trajetória dessa grande heroína do Quilombo dos Palmares e baseada no livro As Lendas de Dandara, da escritora e cordelista Jarrid Arraes. O trabalho tem como intuito valorizar os feitos e a memória de Dandara, contribuindo para a construção da identidade das crianças negras enquanto afrodescendentes, bem como para a inclusão da diversidade étnico-racial nas salas de aula.
\end{abstract}

Palavras-chave: Dandara dos Palmares. As lendas de Dandara. Mulheres negras. História. Literatura.

Abstract: Several black protagonists, such as Dandara dos Palmares, were excluded from the official history of Brazil told in our schools, mainly due not only to racism, among other factors, but also of the machismo and sexism still existing in our society. As one of its consequences is the lack of identification of Afro-descendant girls with black female characters. Thus, this article aims to present a proposal of pedagogical activity through the divulgation of the trajectory of this great heroine of Quilombo dos Palmares, based on the book As Lendas de Dandara, by the writer and cordelist Jarrid Arraes. This work has the purpose of valorizing the deeds and memory of Dandara, and to contribute for the construction of black children's identity as Afro-descendants as well as for the inclusion of ethnic-racial diversity in classrooms.

Keywords: Dandara dos Palmares. The legends of Dandara. Black women. History. Literature.

Introdução

Devido ao racismo e ao sexismo ainda existentes na sociedade brasileira, as mulheres negras foram e continuam sendo sub-representadas nos estudos

\footnotetext{
${ }^{1}$ Mestranda - Curso de Mestrado Profissional em Diversidade e Inclusão (CMPDI) - Programa de Pós-graduação do Instituto de Biologia - Universidade Federal Fluminense - UFF - Brasil

2 Universidade Federal Fluminense
} 
Dossiê: Ensino de História, História das Mulheres e Desigualdades Sociais no Brasil

sobre a História do Brasil, tendo como uma de suas consequências a sua invisibilidade no ambiente escolar. Mesmo após a Lei $n^{\circ} 10.639 / 2003$, a sua inserção se restringe a determinadas temáticas, como a da escravidão, ou em datas específicas, como o Dia da Consciência Negra, na maioria das vezes de forma equivocada e/ou estereotipada, tendo como exemplo clássico a personagem Chica da Silva.

Embora a importância da lei que inclui a obrigatoriedade do ensino da História e Cultura Afro-Brasileira no currículo oficial da rede de ensino seja inegável, sua implementação não vem ocorrendo de forma efetiva, o que, segundo Cordeiro e Pinheiro, se deve desde as divergências entre os currículos hegemônicos e aqueles que evidenciam os conhecimentos negligenciados, perpassando pela deficiência na formação inicial e continuada de docentes, incluindo a falta de investimento público em recursos humanos e materiais, o desconhecimento sobre a lei e a ausência de reconhecimento de sua necessidade nas aulas (CORDEIRO; PINHEIRO, 2018).

Considerando a questão do "esquecimento" das mulheres pela historiografia, Lunz expõe que, desde o aparecimento das primeiras aldeias até a atualidade, o registro das ações realizadas pelas mulheres sempre tiveram menor relevância, especialmente devido ao espaço que a sociedade reservou para o feminino, limitado ao âmbito do privado (LUNZ, 2018).

Contudo, cabe destacar que enquanto as mulheres brancas eram vistas como símbolo de doçura e fragilidade e representadas de forma subordinada e submissa, primeiro ao pai e aos irmãos e, depois, ao marido; as mulheres negras, fossem escravas, forras ou livres, há séculos já trabalhavam nas lavouras ou nas cidades, como vendedoras, quituteiras ou prostitutas, obtendo, em alguns casos, até certo sucesso financeiro (FARIA, 2004).

Assim, se para as mulheres brancas reverter esse cenário de exclusão não seria fácil, pois precisavam vencer a imagem consolidada de sujeito histórico dependente do homem branco, para as mulheres negras, antítese do ser hegemônico, os homens brancos; antítese do ideal feminino, as mulheres brancas (CARNEIRO, 2007, p. 07), a empreitada tornava-se ainda mais complicada, pois além da questão de gênero, precisavam enfrentar a questão de classe e de raça. 
Dossiê: Ensino de História, História das Mulheres e Desigualdades Sociais no Brasil

Como resultado dessa marginalização, as meninas afrodescendentes crescem sem se sentirem representadas e inspiradas por mulheres negras como elas. Por isso é fundamental contarmos também o outro lado da história, aquele que não foi escrito por "vencedores" e detentores do poder, mas por homens e por mulheres que lutaram contra a subjugação de colonizadores.

Através da colonialidade, a Europa impôs um modelo único e universal de conhecimento, reprimindo as epistemologias, os saberes, o mundo simbólico e as imagens de povos localizados na periferia ocidental. O imaginário do outro foi invadido e destruído por colonizadores, que infligiram suas concepções, inviabilizando, subalternizando e ocidentalizando aqueles que foram colonizados (OLIVEIRA; CANDAU, 2010).

Desse modo, os conhecimentos e as histórias de não europeus foram (e permanecem sendo) negados, silenciados e, consequentemente, esquecidos. Conforme Oliveira e Candau, isso se operacionalizou pela sedução, pelo fetichismo e pela atração que a cultura, as ideias e os saberes da Europa exerceram sobre quem foi colonizado (OLIVEIRA; CANDAU, 2010).

Assim, o eurocentrismo foi adotado não apenas por europeus, mas por todos aqueles que foram educados sob sua supremacia. Tal fato nos permite compreender a profusão de conteúdos sobre os acontecimentos ocorridos no continente europeu nos livros didáticos de História, em detrimento de temas referentes à África, Ásia e, até mesmo, América.

As formas de produção de conhecimento não europeias e o legado histórico-intelectual de nativos da América e da África, considerados primitivos e irracionais, foram negligenciados por não pertencerem à "raça" branca, como explicitou Quijano (2007 apud OLIVEIRA; CANDAU, 2010) por meio da definição de colonialidade do saber. Ainda nesse sentido, através da colonialidade do ser, esses povos tiveram sua humanidade negada.

Contrapondo-se a essa perspectiva, a decolonialidade propõe, a partir da valorização e da difusão dos conhecimentos e das lutas de povos historicamente subalternizados, questionar a epistemologia dominante e construir novas formas de ser, poder e saber (WALSH, 2005 apud OLIVEIRA; CANDAU, 2010). Uma delas é a afrocentricidade, conceito desenvolvido pelo professor e filósofo afroamericano Molefi Asante. 
Dossiê: Ensino de História, História das Mulheres e Desigualdades Sociais no Brasil

Em contraposição ao eurocentrismo predominante em muitas abordagens históricas, podemos adotar uma perspectiva afrocentrada. Através dela, é possível ressaltar o papel da pessoa de origem africana como sujeito de sua própria história, lugar do qual sempre foi excluída, e as contribuições da África para a humanidade, reafirmando sua posição central (ASANTE, 2016).

Desse modo, não correremos o risco de uma única história da negritude e do continente africano, para dialogarmos com a feminista e escritora nigeriana Chimamanda Adichie, escrita sob um único ponto de vista, o da Europa. Para a autora, mostrando-se somente uma perspectiva, é possível criar apenas uma única história (ADICHIE, 2013).

Tal fato é perceptível quando questionamos as pessoas sobre o papel de mulheres e homens negros na construção de nossa sociedade. A grande maioria os identificam apenas enquanto mão-de-obra escravizada. Isso se deve à forma como sempre foram retratados nas aulas, nos livros didáticos, sobretudo de História, e em vários filmes e novelas. Sobre eles construiu-se uma única narrativa, a de escravizados, e assim se tornaram no imaginário popular.

Do mesmo modo, quando nos referimos à África as imagens que vêm à lembrança são as de guerras, de fome, de pobreza, de animais selvagens. Sabemos que tudo isso faz parte da realidade africana, mas o continente não se restringe a isso. Alberto da Costa e Silva, no livro A África explicada aos meus filhos, nos revelou os mistérios e a riqueza cultural desse continente tão fascinante.

Além da civilização egípcia, cuja localização na África é ignorada por muitos, reinos poderosíssimos também se desenvolveram por lá, como o do Benim, o de Gana e o de Mali. Sobre o reino de Gana, conhecido como o país do ouro, por exemplo, o autor nos forneceu valiosas informações:

O soberano vestia uma ampla túnica e tinha na cabeça um turbante encimado por um gorro bordado em ouro. Trazia colares e pulseiras também de ouro. Atrás dele ficavam dez escravos, com espadas e escudos ornamentados de ouro. De ouro eram os arreios dos cavalos do rei. $\mathrm{E}$ as coleiras dos cachorros. Conta mais Al-Bakri [árabe que descreveu o rei e sua corte]: que o rei amarrava um de seus corcéis a uma pedra de ouro que pesava 14 quilos (SILVA, 2012, p. 24/5). 
"Como são contadas, quem as conta, quando e quantas histórias são contadas, tudo isso realmente depende do poder", afirma Adichie, que o define como a "habilidade de não só contar a história de outra pessoa, mas de fazê-la a história definitiva daquela pessoa" (ADICHIE, 2013).

O problema, entretanto, ainda está na estrutura na qual estamos pautados onde apenas o grupo localizado no poder tem legitimidade para falar, e onde somente seus conhecimentos e suas produções intelectuais são valorizados.

Os saberes de grupos historicamente silenciados, como negros e indígenas, permanecem marginalizados, como destaca a filósofa, feminista, escritora e acadêmica negra Djamila Ribeiro. Quando nos referimos especificamente às mulheres negras, destaca a autora, a exclusão é ainda maior, havendo tentativas de desautorizar seus escritos (RIBEIRO, 2019).

Apenas a partir da segunda metade do século $X X$ as mulheres começaram a ser vistas como objeto e sujeito da História, sobretudo devido às transformações ocorridas na historiografia, principalmente com as contribuições da nova História Cultural e com a inserção da categoria gênero, a qual reconheceu a multiplicidade de sujeitos não abarcados pela categoria mulher, e ao movimento feminista, promovendo o surgimento de uma História das Mulheres (LUNZ, 2018).

Contudo, apesar de sua relevância, as novas abordagens não foram suficientes para romper completamente com o silêncio que envolve as mulheres, nomeadamente as negras. É preciso considerar que as mulheres negras estão na base da pirâmide social, seguidas pelos homens negros, pelas mulheres brancas e, no topo, pelos homens brancos.

Essas mulheres negras da atualidade são atravessadas por diferentes e complexas opressões estruturais: de raça, de classe, de gênero, de sexualidade, as quais caracterizam a interseccionalidade (XAVIER, 2019). Kimberlé Crenshaw, pesquisadora e ativista afro-americana, definiu o termo como:

Uma conceituação do problema que busca capturar as consequências estruturais e dinâmicas da interação entre dois ou mais eixos da subordinação. Ela (a interseccionalidade) trata especificamente da forma pela qual o racismo, o patriarcalismo, 
Dossiê: Ensino de História, História das Mulheres e Desigualdades Sociais no Brasil

a opressão de classe e outros sistemas discriminatórios criam desigualdades básicas que estruturam as posições relativas de mulheres, raças, etnias, classes e outras (CRENSHAW, 2002, p.177).

Essas múltiplas subordinações, chamadas pela autora de eixos de poder, embora diferentes, se sobrepõem e se intercruzam, atuando como dispositivos que contribuem para as desigualdades e dando origem a complexas intersecções, nas quais duas, três ou quatro categorias convergem. Crenshaw utiliza uma metáfora que facilita bastante $\mathrm{o}$ entendimento do conceito (CRENSHAW, 2002).

Ela propõe que imaginemos a raça, a etnia, o gênero e a classe como vias que compõem os terrenos sociais, econômicos e políticos da sociedade. As mulheres negras, por exemplo, estão localizadas num ponto onde essas vias se encontram, podendo ser atingidas pelo intenso tráfego simultâneo proveniente de todas as direções (CRENSHAW, 2002).

De tal modo, as experiências interseccionais compartilhadas pelas mulheres negras são expressão do lugar social comum por elas ocupado. Nesse local subalternizado elas são submetidas a condições sociais desiguais, hierárquicas e não humanizadas, as quais invisibilizam e deslegitimam seus fazeres, seus saberes e suas vozes e as impedem de acessarem determinados espaços, como as universidades.

Sua ausência nesses espaços contribui para a supressão das produções e das epistemologias de seu grupo. Ribeiro nos faz refletir sobre essa questão com uma simples pergunta: quantas autoras e autores negros o leitor e a leitora, que cursaram a faculdade, leram ou tiveram acesso durante o período da graduação? (RIBEIRO, 2019, p. 63).

As pessoas negras, tradicionalmente, foram e continuam sendo impedidas de falar. Não obstante, esse falar não se limita ao ato de proferir palavras, mas inclui à possibilidade de existir humanamente. Isso demonstra o quanto o lugar social ocupado por um grupo pode lhe garantir privilégios ou restringir-lhes oportunidades (RIBEIRO, 2019).

Por isso, pensar sobre lugar de fala nos faz questionar a legitimidade atribuída exclusivamente ao grupo localizado no poder, à historiografia 
Dossiê: Ensino de História, História das Mulheres e Desigualdades Sociais no Brasil tradicional e à hierarquização de saberes, resultante da estratificação social, e reivindicar a existência de uma multiplicidade de vozes e conhecimentos capazes de romper com o discurso único e supostamente universal, então em vigor (RIBEIRO, 2019).

Contudo, isso não é nem será uma missão fácil, pois seguramente as vozes de grupos discriminados, por sua potência e por trazerem à tona verdades até então encobertas pelo manto da dominação, irão incomodar aqueles que sempre estiveram no poder, gerando conflitos muitas vezes inevitáveis.

Mas, é chegada à hora das mulheres e homens negros escreverem as suas próprias histórias, pois, como disse Adichie, muitas histórias importam (ADICHIE, 2013). Se, durante longo tempo, elas foram utilizadas para expropriar esses sujeitos e retirar sua dignidade, agora elas poderão servir para capacitar, humanizar e devolver o orgulho a esses indivíduos.

Com certeza, a inclusão desses atores negros permitirá a geração de narrativas totalmente diferentes das que figuram nos livros didáticos e de literatura, posto que as experiências resultantes do lugar social que Ihes foi imposto, e, consequentemente, pontos de vista e lugar de fala, são diferentes dos do homem branco, seguidor da cartilha europeia, oriundo de outro lócus social.

A presença das mulheres negras nos livros didáticos e paradidáticos, como autoras e/ou como personagens representadas positivamente, nas aulas e nas atividades escolares como um todo, sempre foi bastante rara na vida das autoras deste trabalho, quando não inexistente, como muito provavelmente ocorreu (e infelizmente continua ocorrendo) na trajetória de muitas crianças.

Foi esse sentimento que nos levou a pesquisar mais sobre Dandara, uma das lideranças femininas do Quilombo dos Palmares, posto que queríamos que as crianças negras, sobretudo as meninas, tivessem a oportunidade que não tivemos, que conhecessem as narrativas dessa grande guerreira e se encantassem com elas, descobrindo a sua relevância para a formação de nosso país, com a consciência de que o povo negro foi e é sujeito da História no Brasil.

Assim, o objetivo deste artigo é auxiliar a prática pedagógica de docentes do ensino básico a partir da divulgação da trajetória de Dandara dos Palmares, buscando contribuir para a valorização de suas memórias, o reconhecimento de 


\section{HISTÓRIA}

Dossiê: Ensino de História, História das Mulheres e Desigualdades Sociais no Brasil seus feitos, e a construção da identidade das meninas negras enquanto afrodescendentes, através de sua identificação com essa grande guerreira, símbolo de liberdade.

Para tanto, propomos uma atividade para ser realizada em sala de aula com o livro paradidático As lendas de Dandara, da escritora e cordelista Jarrid Arraes (2015). A proposta pode ser desenvolvida de forma interdisciplinar; dentro dos conteúdos sobre o Brasil Colônia e Império, nos quais discutimos sobre os quilombos; nas comemorações de 20 de novembro; no Dia Internacional da Mulher ou em qualquer outro momento considerado oportuno pela equipe pedagógica, com turmas do Ensino Fundamental ou Médio.

Dandara e o Quilombo dos Palmares- selecionando a história a se familiarizar

Durante muito tempo, a historiografia oficial manteve o Quilombo dos Palmares negligenciado em suas produções, contudo, a partir da década de 1970, a comunidade e seu líder, Zumbi, converteram-se em símbolos da luta contra a opressão no Brasil, sendo resgatados principalmente pelo movimento negro. Apesar disso, uma de suas grandes guerreiras permaneceu silenciada: Dandara dos Palmares.

A história dessa heroína, que, no século XVII, liderou homens e mulheres em vários conflitos contra as forças enviadas pelas autoridades coloniais, em defesa de Palmares, e transformou-se em ícone da liberdade e do combate à escravidão, é cercada de incertezas e os registros sobre ela são muito limitados.

Sua real existência é questionada por alguns autores, os quais a consideram um mito do passado do Quilombo dos Palmares. Nei Lopes, no pequeno verbete que escreveu sobre ela na Enciclopédia brasileira da diáspora africana, diz que Dandara é uma personagem lendária da história de Palmares e que sua vivência está ainda envolta em uma aura de lenda (LOPES, 2004, p.42).

Maurício Ayer, seguindo a mesma linha de raciocínio, afirma que a guerreira pertence à mitologia palmarina e que não há evidências históricas sobre ela. $\mathrm{O}$ autor questiona 
(...) se a personagem de Dandara não teria sido criada por uma necessidade de suprir a lacuna de que o herói Zumbi - ele também fusão de mito e história - tivesse uma companheira tão forte e valente quanto ele, capaz de encarnar rebeldia e libertação. Em contraposição a uma mitologizante tendência da história oficial de apagar o que não interessa aos vencedores, não haveria uma tendência popular - igualmente mitologizante - de forjar figuras que apontem para um mundo mais completo? (AYER, 2015).

Outros estudos, segundo Arraes, sugerem que Dandara pode ter sido confundida com alguma liderança do quilombo. Entretanto, para a autora, o grande problema é o fato de, devido ao machismo e ao racismo presentes em nossa sociedade, a guerreira não ser devidamente mencionada na historiografia brasileira (ARRAES, 2015).

A historiadora Sandra Santos, mencionando as mesmas questões colocadas por Arraes, as quais influenciam negativamente a produção historiográfica e os livros didáticos fazendo com que não contemplem personagens femininas negras como Dandara, diz que, apesar dos obstáculos, essas mulheres persistem no imaginário do povo e por ele são reconstruídas, dando origem a contos e lendas que as transformam em mitos (TINOCO, 2014).

Souza e Cararo, na apresentação de seu livro, Extraordinárias - Mulheres que revolucionaram o Brasil, também falam sobre esse ponto, afirmando que no caso de nossa guerreira não há como distinguir com exatidão o que é mito e o que é fato histórico (SOUZA; CARARO, 2017).

Por conseguinte, sendo mito ou não, a história de Dandara é uma verdade coletiva e historicamente consagrada pela repetição ao longo do tempo, através dos relatos e lendas populares (BRANDÃO, 2009). Por isso, merece e precisa ser estimulada e reproduzida sob o ponto de vista didático-pedagógico, de forma autônoma, dissociada da figura masculina de Zumbi, constituindo-se em uma referência positiva da negritude para as crianças e rompendo com o discurso preconceituoso predominante no Brasil. Como destaca Arraes, Dandara vive e sua memória nunca poderá ser apagada (ARRAES, 2015, p. 15). 
Dossiê: Ensino de História, História das Mulheres e Desigualdades Sociais no Brasil

Nesse sentido, cabe destacar que seu nome consta no Livro dos Heróis e Heroínas da Pátria, tendo sido inserido pela Lei nº 13.816/2019, e no calendário oficial do estado do Rio de Janeiro, após a aprovação da Lei $n^{\circ} 7.270 / 2016$, com o Dia de Dandara e da Consciência da Mulher Negra, celebrado em 06 de fevereiro.

Partindo para as investigações sobre a vida de nossa guerreira, verificamos que sua procedência é desconhecida, não se sabe se ela veio da África ou se nasceu no Brasil. Alguns estudos, conforme Maria de Lourdes Siqueira, todavia, mencionam uma ascendência na nação africana Jeje Mahin, no Benin (TINOCO, 2014). No entanto, o que se tem de concreto até o momento é que ela teria se juntado aos palmarinos ainda muito jovem.

O Quilombo dos Palmares, cujo nome derivava da grande quantidade de palmeiras existentes na região - a pindoba, em maior número, e a ouricuri, a catolé e a tirara, menos expressivas - estabeleceu-se na Serra da Barriga (CARNEIRO, 1958), região que atualmente pertence ao município de União dos Palmares, no estado de Alagoas, mas que à época fazia parte da capitania de Pernambuco.

O local foi tombado, em 1986, pelo Instituto do Patrimônio Histórico e Artístico Nacional (Iphan), tornando-se Patrimônio Cultural Brasileiro, e em 2007 foi transformado no Parque Memorial Quilombo dos Palmares, o qual busca reconstituir o espaço físico do quilombo.

Segundo Simone Rezende da Silva e Lisangela Kati do Nascimento, os quilombos foram uma das primeiras formas de atuação de sujeitos negros contra a escravização, a discriminação racial e o preconceito, constituindo-se como espaços de liberdade (SILVA; NASCIMENTO, 2012). Apesar disso, essa forma de organização ainda permanece envolta em concepções equivocadas, as quais se fazem presentes nos livros didáticos.

Difundiu-se a crença na existência de um modelo único de quilombo, o modelo Palmariano, em referência ao Quilombo dos Palmares. Tal percepção, de acordo com Correa, baseava-se na relação fuga-conflito e na definição de quilombo utilizada pelo Conselho Ultramarino de Portugal: toda habitação de negros fugidos, que passem de cinco, em parte despovoada, ainda que não tenham ranchos levantados e nem se achem pilões nele (CORREA, 2011, p. 39). 
Dossiê: Ensino de História, História das Mulheres e Desigualdades Sociais no Brasil

Porém, análises recentes vêm ressaltando a diversidade de tipos, tamanhos e origens dos quilombos que se formaram no Brasil, sendo o de Dandara e Zumbi dos Palmares uma exceção, não a regra. Além disso, têm colocado ênfase não na fuga, mas na resistência e autonomia daqueles que organizaram os quilombos (CORREA, 2011).

O Quilombo dos Palmares começou a ser formado no início do XVII, quando a economia açucareira estava em decadência, mantendo-se atuante praticamente durante todo o século (CARNEIRO, 1958). Entre todos os quilombos que se formaram no Brasil, Palmares é o mais conhecido e estudado, sendo o que mais tempo durou, de 1597 a 1695, o que ocupou maior área territorial e o que mais trabalho deu às autoridades coloniais para ser eliminado (MOURA, 1986).

O ápice de seu crescimento se deu por volta de 1630, durante a conquista holandesa no Nordeste brasileiro, quando os conflitos dela resultante desorganizaram a sociedade colonial e desviaram a atenção dos senhores, criando um ambiente propício para a fuga de escravizados (CARNEIRO, 1958).

Entre os residentes no quilombo, cujo número pode ter chegado a até 50 mil indivíduos, em seu auge (SOUZA; CARARO, 2017), havia também indígenas e pessoas brancas. Das matas, extremamente férteis, retiravam parte de seu sustento, os materiais utilizados na construção de suas moradias e na proteção do quilombo e os metais necessários para a fabricação de ferramentas e armas (CARNEIRO,1958).

Além disso, caçavam, criavam animais, principalmente galinhas, e praticavam a agricultura. O principal produto era o milho, mas cultivavam igualmente feijão, batata-doce, mandioca, banana e cana-de-açúcar. O excedente era comercializado nas vilas e engenhos próximos (MOURA, 1986).

Também desenvolveram a cerâmica, construindo panelas e vasos de barro, cuias de coco, cestos, esteiras e abanos, e fizeram trabalhos em cabaças. Em suas incursões pela região cativavam várias pessoas. Algumas iam de forma voluntária, outras compulsoriamente. Nesse último caso, eram escravizadas e obrigadas a trabalhar na agricultura (CARNEIRO, 1958).

Cabe lembrar que a escravidão já era uma instituição existente na África antes da presença europeia. Não obstante, esta transformou uma prática 


\section{HISTÓRIA}

Dossiê: Ensino de História, História das Mulheres e Desigualdades Sociais no Brasil

predominantemente doméstica em um comércio transatlântico de grandes proporções. Calcula-se que aproximadamente 12,5 milhões de seres humanos foram enviados à força para as Américas, sendo entre 4 e 5 milhões somente para o Brasil.

Vale destacar ainda que não eram africanos escravizando africanos, visto que os povos do continente se identificavam como mandingas, fulas, axantes, dentre outros, mas não como africanos. Assim, eles escravizavam o outro, o estranho, não o igual (SILVA, 2012).

Além disso, aqueles que eram mantidos como escravizados em Palmares não recebiam o mesmo tratamento do cativeiro colonial-mercantil, nem permaneciam indefinidamente nessa situação (SILVA, 2014). Uma das formas de se obter a alforria, por exemplo, era levar para Palmares alguém como cativo (CARNEIRO, 1958).

Palmares era composto por vários quilombos ou mocambos, como podemos observar no trecho abaixo:

(...) um documento da época informava que, a dezesseis léguas de Porto Calvo, ficava o mocambo do Zumbi; cinco léguas mais ao norte, o mocambo de Acotirene; a leste destes, dois mocambos chamados Tabocas; léguas a noroeste destes mocambos, o de Dambrabanga; oito léguas mais ao norte, a "cerca" de Subupira; seis léguas mais ao norte, a "cerca real" do Macaco; cinco léguas a oeste, o mocambo de Osenga; a nove léguas de Serinhaém, para noroeste, a "cerca" do Amaro; a vinte e cinco léguas de Alagoas, para noroeste, o "palmar" de Andalaquituche, irmão do Zumbi; a vinte cinco léguas a noroeste de Porto Calvo, o mocambo de Aqualtune, mãe do rei; "e entre todos estes, que são os maiores e mais defensáveis, há outros de menor conta e de menor gente" (CARNEIRO, 1958, p. 57).

Cada mocambo possuía uma chefia, com poderes absolutos. Apenas em momentos de guerra ou em determinadas situações de interesse de toda a comunidade, as lideranças se reuniam na Casa do Conselho, no mocambo do Macaco, capital do quilombo e residência do monarca, Ganga-Zumba, a quem cabia as principais decisões (MOURA, 1986).

Não há consenso entre as pesquisas sobre a organização estabelecida em Palmares. Segundo algumas, os quilombos mantiveram uma configuração 
Dossiê: Ensino de História, História das Mulheres e Desigualdades Sociais no Brasil

bem semelhante àquela existente nas aldeias africanas. De acordo como outras, as comunidades apresentavam uma combinação de aspectos africanos, europeus e ameríndios. O material arqueológico encontrado na Serra da Barriga corrobora com essa concepção, revelando a diversidade das influências culturais presentes no assentamento (FUNARI, 2001).

Como liderança feminina negra, Dandara não poupava esforços na defesa do quilombo, sendo sua principal missão protegê-lo (SOUZA; CARARO, 2017). Participava na ordenação da comunidade, na elaboração das estratégias de resistência e atuava em todas as batalhas, sendo, conforme contam, exímia guerreira, conhecedora de determinadas técnicas de luta.

Alguns relatos e narrativas citam sua habilidade como capoeirista. Entretanto, não localizamos nenhuma referência concreta do exercício da capoeira em Palmares. A origem da prática ainda é uma incógnita nos estudos sobre o tema, podendo ser considerada africana, brasileira ou afro-brasileira.

Segundo esta última concepção, a mais aceita, a capoeira foi criada em solo brasileiro por sujeitos africanos e seus descendentes, durante o período escravocrata (MACUL, 2008). Corroborando com essa análise, Lussac e Tubino afirmam que seu desenvolvimento ocorreu durante o Brasil Colônia, apresentando diferentes configurações no tempo e no espaço (LUSSAC; TUBINO, 2009).

Os registros sobre a capoeira são mais significativos a partir do século XIX. Ayer diz que na Colônia, o que se comentava era a respeito da grande habilidade quilombola na guerra, sendo o grupo de Palmares considerado um inimigo mais destemido do que o dos invasores holandeses, pois empregava técnicas de luta que o tornava praticamente invencível (AYER, 2015).

Dandara perseguia incansavelmente a liberdade e, por ela, se negava a aceitar o acordo de paz firmado por Ganga-Zumba com o governo da capitania de Pernambuco, em 1678, que previa a concessão de um terreno para a moradia dos habitantes do quilombo, em local por eles escolhido, a liberdade de todos aqueles nascidos em Palmares, a devolução das mulheres capturadas e o direito ao comércio, mas obrigava-os a entregar escravizados que procurassem sua ajuda (SOUZA; CARARO; 2017). 


\section{HISTÓRIA}

Dossiê: Ensino de História, História das Mulheres e Desigualdades Sociais no Brasil

Opondo-se ao monarca, Dandara aliou-se a Zumbi, que também era contrário ao tratado. A sua posição acabou influenciando a decisão de outras lideranças, sendo fundamental para a ruptura entre Zumbi e seu tio GangaZumba, o qual acabaria assassinado por um de seus antagonistas (SOUZA; CARARO; 2017).

Além de grande guerreira, Dandara ainda foi esposa e mãe. Tornou-se a primeira e única companheira de Zumbi, que com a morte de Ganga-Zumba passou a liderar o quilombo, retomando o conflito com as autoridades portuguesas. Com ele teve três filhos: Motumbo, Harmódio e Aristogíton.

Infelizmente, não ficaram registros iconográficos de nossa aguerrida heroína, mas, de acordo com Siqueira, poderíamos descrevê-la como uma mulher forte, bela, guerreira, persuasiva, líder e obstinada por liberdade (TINOCO, 2014).

Acredita-se que Dandara tenha morrido em 06 de fevereiro de 1694 com a destruição do Quilombo dos Palmares pela tropa do paulista Domingos Jorge Velho, após ferrenha e heroica resistência imposta pela comunidade quilombola. De acordo com alguns relatos, ela teria se jogado de um penhasco para não se submeter aos inimigos (SOUZA; CARARO, 2017).

Proposta de atividade escolar sobre Dandara e sua história

Como destacamos anteriormente, as personagens femininas, sobretudo as negras, foram, durante muito tempo, excluídas da História oficial de nosso país e, consequentemente, dos livros didáticos. Atualmente, embora as pesquisas venham avançando de modo a reverter esse quadro e a incluir as mulheres como protagonistas que foram e são da formação do Brasil, é perceptível a ausência das integrantes do povo negro nos conteúdos escolares.

De uma forma geral, as pessoas negras só aparecem nas aulas de História quando o assunto é a escravidão e, mesmo assim, sua inserção é basicamente restrita ao trabalho, aos episódios de tortura ou a algumas manifestações culturais, como a capoeira. Pouco espaço é reservado para se 
Dossiê: Ensino de História, História das Mulheres e Desigualdades Sociais no Brasil

abordar as negociações estabelecidas com os senhores e as diversas formas de resistência empreendidas, como é o caso dos quilombos.

Dentro deste contexto, neste artigo, sugerimos o desenvolvimento de uma atividade pedagógica com o objetivo não só de divulgar a biografia e as ações de Dandara dos Palmares, mas também de refletir sobre a marginalização das personagens femininas negras nas escolas, nos livros didáticos e nos meios de comunicação, o que contribui significativamente para a manutenção do preconceito racial em nossa sociedade.

Assim, após discutir sobre o silenciamento das personagens femininas negras nas escolas e nos livros didáticos e apresentar sucintamente nossa heroína, propomos a docentes e discentes um mergulho na trajetória de Dandara dos Palmares através do livro As lendas de Dandara, de Jarid Arraes (2015).

O material foi organizado com base na experiência da autora principal como professora de História, sobretudo no Ensino Fundamental, em uma escola da rede estadual de ensino no município de Duque de Caxias. Tendo consciência das diversas realidades encontradas nas salas de aula, essas sugestões podem e devem ser adaptadas de modo a melhor atender às necessidades das turmas.

Conquanto exista discordância entre os estudos sobre o conceito de literatura afro-brasileira, ainda em construção, consideramos, com base na interpretação de Eduardo de Assis Duarte, As lendas de Dandara como pertencente a esse campo. Segundo o autor, literatura afro-brasileira é aquela que possui:

(...) uma voz autoral afrodescendente, explícita ou não no discurso; temas afro-brasileiros; construções linguísticas marcadas por uma afro-brasilidade de tom, ritmo, sintaxe ou sentido; um projeto de transitividade discursiva, explícito ou não, com vistas ao universo recepcional; mas, sobretudo, um ponto de vista ou lugar de enunciação política e culturalmente identificado à afrodescendência (DUARTE, 2014, p.385).

Descendente de africanos, a cordelista, escritora e feminista Jarid Arraes se identifica enquanto tal e utiliza seus textos como instrumento de luta, abordando a temática negra e feminina, em defesa de seus direitos e contra o preconceito racial e sexista. 
Dossiê: Ensino de História, História das Mulheres e Desigualdades Sociais no Brasil

Consideramos que esse seria um excelente ponto de partida para introduzir o trabalho com a obra em sala de aula, a partir de uma conversa com o grupo sobre a autora e sua militância. A biografia de Jarrid Arraes, assim como o livro, nas versões impressa e digital podem ser encontrados na página da autora na internet: http://jaridarraes.com.

Em seguida, deve ser explorada a capa do livro, na qual se destaca a ilustração de nossa guerreira palmarina. Nela seus atributos físicos, sobretudo a pele preta e os cabelos crespos, são valorizados e exaltados, o que é extremamente relevante, pois, conforme Lima, as imagens ilustradas também constroem enredos e cristalizam as percepções sobre aquele mundo imaginado (LIMA, 2000 apud OLIVEIRA, 2003, p.16). Deste modo, elas são essenciais para desconstruir estereótipos e prejulgamentos.

Caso se queira propor uma discussão com a turma sobre essa questão da valorização dos cabelos crespos, sugerimos um pequeno vídeo intitulado Cabelo duro? Carolina afirma que não!, feito por uma menina negra de sete anos e disponível no endereço https://youtube.com/watch?v=d1d0JxGTGOg. Carolina é uma menina que faz críticas àqueles que dizem que seu cabelo é duro e tentam convencê-la a alisá-lo. Satisfeita consigo mesma, Carolina deixa claro para todos que é feliz e não tem a mínima intenção de mudar.

Além de ressaltarem o fenótipo da mulher negra, Arraes e a ilustradora Aline Valek rompem com o lugar-comum imposto às guerreiras, caracterizadas como fortes e musculosas, tendo como exemplo máximo as amazonas. À Dandara, ao contrário, conferem o biotipo de uma mulher comum, como tantas outras de sua época e atuais, estando sua verdadeira força em suas atitudes e ideais.

$\mathrm{Na}$ construção do texto, a afrobrasilidade também está presente. Arraes fez questão de designar personagens negros com nomes africanos, como Bayô (alegria encontrada), Kambo (sem sorte), Sanjo (o que aprecia seu passado) e Mali (riqueza), uma crítica à prática recorrente no Brasil do período escravista de renomear aqueles submetidos ao cativeiro com nomes cristãos e sobrenomes de seus senhores (FROES, 2009). Tal ação, conforme a autora, contribuiu para que milhares de afrodescendentes deixassem de conhecer suas origens (ARRAES, 2015). 
Dossiê: Ensino de História, História das Mulheres e Desigualdades Sociais no Brasil

Ademais, a escritora transforma uma insígnia africana, a akofena, em instrumento de luta para nossa heroína. De acordo com Elisa Larkin Nascimento e Luiz Carlos Gá, a akofena é um símbolo de autoridade, legitimidade do estado e das façanhas heroicas (NASCIMENTO; GÁ, 2009, p. 35), algo bem apropriado para Dandara dos Palmares.

Feitas essas considerações iniciais, é hora de mergulharmos na leitura do livro, uma ficção, do gênero narrativo, baseada na História do Brasil e nas informações disponíveis sobre a guerreira palmarina. Dentre os dez contos com que foi organizada a obra, propomos a leitura e a análise de cinco: O Nascimento de Dandara, O Navio Negreiro, Fogo na Casa Grande, Senzalas Vazias e A Pedreira.

Para a realização dessa atividade, o ideal seria que cada discente pudesse dispor de um livro. Contudo, levando-se em consideração a situação das escolas públicas do estado do Rio de Janeiro, sugerimos que a turma seja dividida em grupos e que cada um deles receba um conto. Ressaltamos ainda que a escolha das cinco histórias não impede que as demais sejam trabalhadas.

Recomendamos a seleção de trechos dos capítulos escolhidos para serem recitados, primeiramente por aquele que está conduzindo a atividade e, depois, por integrantes do grupo que se sentirem à vontade para fazê-lo. No decorrer da atividade, toda a turma deverá ser incentivada a ler em voz alta.

O Nascimento de Dandara. Leitura do primeiro parágrafo da página 18 , no qual é revelada a razão da tristeza de África: Revisitava as cenas do passado, assistindo milhares de filhos embarcando forçadamente, como mercadorias, em navios que vinham de lugares longínquos. Essa passagem é fundamental para a verificação do que a turma sabe sobre a escravidão africana, corrigir possíveis erros e ampliar as discussões.

Do quarto e do sexto parágrafos da página 21 , que mostram a solução encontrada por lansã para resolver o problema: São todos homens! Homens alvos; Criarei uma guerreira, filha do meu ser, que libertará seus irmãos e irmãs! Esse seria um bom momento para a turma debater sobre a questão de gênero, visto que uma mulher foi a escolhida para lutar contra conquistadores provenientes da Europa e resgatar aqueles que foram submetidos à escravidão. 
Dossiê: Ensino de História, História das Mulheres e Desigualdades Sociais no Brasil

Como mencionamos anteriormente, a procedência de Dandara é ignorada e, para muitos, nossa heroína nunca existiu, sendo apenas uma lenda. Em resposta aos incrédulos, Arraes decidiu então encarar a ideia das lendas como uma provocação e uma oportunidade. Pensei comigo mesma: se Dandara é uma lenda, alguém precisa escrever suas lendas (ARRAES, 2015, p.12).

De tal modo, a autora recorre à liberdade poética para criar uma origem para a líder quilombola. Fundamentando-se nos critérios filosófico-literários da tradição e nas ideias concernentes à cosmogonia iorubá, ou seja, à sua forma de interpretar o surgimento do universo, ela atribui a maternidade de Dandara à lansã ou Oyá, orixá das tempestades e ventanias, o que, somado à sua personalidade forte, de acordo com a autora, a transformava na mãe ideal para nossa guerreira, que herdaria suas características.

Os orixás eram divindades cultuadas no continente africano apenas por iorubas ou nagôs (SILVA, 2012), sendo responsáveis por fazer a intermediação entre as pessoas e Olorum, Deus supremo. Na África, havia aproximadamente seiscentos orixás. Cada grupo venerava um ou mais orixás em particular. Para o Brasil, junto com os iorubas, vieram cerca de cinquenta orixás.

Do contato entre os indivíduos que prestavam reverência a diferentes orixás, nasceriam as religiões de matriz africana, como é exemplo o candomblé (ZACHARIAS, 1998 apud PORTZ, 2011). Cada orixá é responsável por cuidar de uma determinada parte da natureza e controlar uma particularidade do ser humano e das relações sociais.

Dessa maneira, determinado orixá cuida do raio, outro da chuva, outros do mar, das colheitas, do comércio, das relações amorosas, do equilíbrio emocional, da justiça etc. Exu, Ogum, Oxóssi, Iroco, Ibejis, Nanã, Omolu, OxumarêEuá, Ossaim, Xangô, Obá, Oxum, lemanjá, Oxalá são algumas dessas divindades (PRANDI, 2004).

Leitura de toda a página 22, que fala da criação de Dandara, observandose esse trecho: A medida que convocava nuvens e ventos para compor sua criação, lansã ordenava que uma tempestade se formasse. (...) Minha filha será uma extensão de $\operatorname{mim}($...).

Do segundo parágrafo da página 23, o qual revela como nossa heroína chegou ao Brasil: Dandara viajou por todo o oceano nos braços de lansã, até 
Dossiê: Ensino de História, História das Mulheres e Desigualdades Sociais no Brasil que chegassem ao novo continente aonde os filhos de África haviam sido levados; e do terceiro da página 24, que mostra como Dandara foi colocada no caminho de Bayô: lansã então adiantou-se no caminho que a mulher percorria, com a intenção de deixar Dandara para que fosse resgatada pela fugitiva. Lembremos que, segundo os dados existentes, nossa guerreira estaria desde criança no quilombo.

Tal tema normalmente gera muitas críticas e oposição quando é inserido na escola, tanto por parte da direção quanto pelos pais e pela comunidade, devido à cultura eurocêntrica cristã enraizada em nossa sociedade que, por se entender superior, desvaloriza o que é diferente e, além disso, cultiva uma concepção de ser e estar no mundo calcada em ambivalências excludentes.

Devido a isso as divindades africanas são erroneamente associadas à malignidade. Exu, por exemplo, desde os primeiros contatos de missionários europeus com o povo ioruba foi identificado com o diabo (criação europeia) e assim permanece até os dias de hoje (PRANDI, 2001 apud PORTZ, 2011).

Para concluir essa primeira parte das lendas, leitura do segundo e terceiro parágrafos da página 26 que mencionam a missão da líder palmarina: lansã estava certa de que sempre acompanharia o crescimento de sua filha e faria de tudo para que ela se tornasse uma guerreira impetuosa, pronta para livrar seus irmãos da tirania dos homens brancos.

Essa narrativa igualmente possibilita que outros assuntos sejam explorados, como: a África enquanto continente, já que muitas pessoas ainda a identificam como um país; a escravidão em território africano; o tráfico de indivíduos escravizados; as motivações europeias para o uso da mão-de-obra africana; as teorias raciais do século XIX; e a formação dos quilombos no Brasil.

O Navio Negreiro e Fogo na Casa Grande. Nessas narrativas a turma mergulha nas aventuras de Dandara, nas quais não faltam ação, coragem, força, heroísmo, determinação, justiça e, sobretudo, uma busca incansável pela liberdade. Nelas é perceptível o protagonismo que a autora confere às mulheres, representadas por Dandara e por outras figuras femininas que ganham destaque ao longo de toda a obra.

A liderança de nossa heroína e a forma respeitosa com que era tratada por todos, fruto de sua capacidade enquanto guerreira, são constantemente 
Dossiê: Ensino de História, História das Mulheres e Desigualdades Sociais no Brasil mencionadas no texto: Dandara percebia que era quase uma unanimidade em Palmares: as crianças das novas gerações cresciam ouvindo histórias de seus feitos (...). Os mais velhos não poupavam elogios (...) (p. 63).

Dandara não se enquadrava nos papéis impostos às mulheres pela sociedade da época e, no livro, Arraes não a restringe à mera função de companheira de Zumbi, pelo contrário, à líder quilombola é dada voz ativa, a ela cabe o treinamento para a guerra, o planejamento das ações, a tomada de decisões. Na clareira, todos os homens se sentaram (...). Dandara (...) apenas aguardou que todos estivessem acomodados no chão e levantou a voz com autoridade (p. 92).

Zumbi também é caracterizado como um grande guerreiro e líder, que por Dandara demonstrava muita consideração, admiração e respeito: Zumbi voltou seu olhar para Dandara, aguardando o complemento de sua sugestão (p. 65). Zumbi se mantinha em pé. (...) estava feliz pelo sucesso da missão, admirado pela capacidade inegável de Dandara e sinceramente tocado (p. 78).

Nessas histórias, embora de modo fantasioso, ganham destaque os ataques que a comunidade quilombola fazia no entorno de Palmares, nos quais libertavam pessoas do cativeiro que com eles seguiam para o quilombo. Aqui é importante, também, ressaltar que muitos homens e mulheres eram levados à força e escravizados pelo grupo, conforme lembramos acima.

Do mesmo modo, é preciso ter cautela ao se referir ao ideal de liberdade de Dandara. De acordo com o texto, o objetivo da guerreira era libertar todos os indivíduos escravizados da região, porém, até mesmo pelo fato de haver pessoas cativas em Palmares, como era comum nas sociedades africanas, e pelas poucas informações disponíveis sobre Dandara, fosse mais adequado direcionar sua luta para a defesa do território palmarino contra as expedições das autoridades coloniais.

Contudo, isso não diminui a importância histórica de nossa personagem, seus feitos, sua bravura e a referência positiva que ela representa, nem tampouco a simbologia do Quilombo do Palmares enquanto local de liberdade. Não podemos esquecer que a África apresenta uma grande diversidade cultural e que a ideia de africano foi criada nas Américas, não havendo essa unidade por lá, como já apontamos. 


\section{HISTÓRIA}

Dossiê: Ensino de História, História das Mulheres e Desigualdades Sociais no Brasil

Com esses contos, é possível ponderar sobre os navios negreiros, também chamados de tumbeiros, e a difícil situação enfrentada durante a travessia do Atlântico; as diferentes línguas faladas em África; e a prática da capoeira no Brasil, a qual é citada no livro, embora não haja registro de sua prática no quilombo.

Para encerrar essa parte da atividade, sugerimos que seja lido em voz alta o segundo parágrafo da página 74: Meu nome é Dandara, sou guerreira dos Palmares e sou uma mulher livre! (grifos nossos), que demonstra todo o orgulho de nossa heroína por ser mulher, negra, guerreira e livre e, certamente, atrairá a empatia das meninas negras.

Senzalas Vazias. Nesse capítulo, importante para o desfecho da história, Dandara conclui a missão que Ihe foi atribuída por lansã: libertar seus irmãos e irmãs. (...) Dandara via aquela noite como o ápice de todas as suas lutas. (...) $A$ missão que tinha Ihe designado finalmente atingia seu cume (p. 121). O sol já aparecia e apenas uma senzala restava para ser invadida. Com o sucesso da estratégia, Zumbi já imaginava o mesmo plano sendo posto em prática em outras regiões (p. 127).

Cabe chamar a atenção da turma para o penúltimo parágrafo da página 132, no qual a autora destaca o papel da negritude, sobretudo da mulher negra, como sujeitos da História, retomando as discussões que iniciaram as atividades.

Tudo parecia imenso, muito grandioso, como as histórias de sagas épicas que escutava quando criança sobre as princesas de África, suas vitórias e suas derrotas. Mas, naquele dia, Mali era a protagonista de sua história. Naquele momento, ela e seus irmãos eram as pessoas mais importantes daquele conto.

A Pedreira. No capítulo decisivo do livro, a pedreira, um dos lugares favoritos de Dandara e local de seu encontro com lansã, será palco da última ação de nossa heroína. Nele, a autora faz alusão à expedição definitiva enviada pelo governo português contra Palmares, sob o comando de Domingos Jorge Velho. Muitas forças foram convocadas pelos homens brancos para que aquele ataque contra Palmares fosse o derradeiro (p. 139).

$\mathrm{Na}$ ocasião, diante do iminente desmantelamento do quilombo, apesar dos esforços empreendidos pela comunidade, Dandara, preferindo a morte às 
Dossiê: Ensino de História, História das Mulheres e Desigualdades Sociais no Brasil humilhações e torturas às quais certamente seria submetida caso fosse capturada, teria se jogado de um penhasco.

- Não vou ser uma dessas! - Esbravejou olhando para a mata atrás de si. - Estão ouvindo?! Jamais serei uma escrava! (p. 143).

Como não há certeza do que realmente aconteceu com nossa guerreira, a autora novamente recorre à fantasia para terminar sua história: após se atirar da pedreira, Dandara se transforma magicamente, subindo aos céus para retornar ao corpo de sua mãe, lansã. Sugerimos que as páginas 144 e 145 sejam lidas, na íntegra, em voz alta, para que a turma acompanhe junta a conclusão da narrativa.

Embora o texto não faça alusão a Ganga-Zumba, tio de Zumbi e primeiro rei de Palmares, é possível ampliar as discussões, remetendo-se à organização política do quilombo, ao monarca e às desavenças entre ele, Zumbi e Dandara a respeito do acordo de paz com as autoridades coloniais, como já observamos.

Outras propostas de trabalho podem, igualmente, ser elaboradas, tais como as sugeridas a seguir:

1- Pedir à turma que selecione outros trechos para a leitura, de acordo com critérios próprios. Explicitar, oralmente ou por escrito, quais foram os critérios utilizados para a escolha. Essa resposta deverá ser acolhida, propiciando um diálogo com o grupo.

2- Pedir que sejam selecionados fragmentos dos capítulos e preparada uma audição dos mesmos, usando a imaginação. Nesse momento, podem-se inserir informações sobre o trabalho artístico e criativo de contadores de histórias e cordelistas e lembrar as performances de rappers e demais artistas urbanos contemporâneos.

O ideal é que a apresentação seja agendada para as aulas vindouras. Pode-se variar o espaço da apresentação: no pátio, na sala de leitura, no auditório, debaixo de uma árvore.

A qualidade da proposta de leitura se efetiva quando a criança ou jovem se sente à vontade para criar e assumir o papel de protagonista na ação. Dessa forma, supõe-se que se tenha atingido um dos principais objetivos do ensino: a transformação da palavra em conhecimento. 
Dossiê: Ensino de História, História das Mulheres e Desigualdades Sociais no Brasil

3 - Por fim, pode-se propor à turma que elabore um novo desfecho para a história de Dandara dos Palmares.

Considerações finais

A diversidade cultural ainda não é plenamente contemplada em nossas escolas, apesar da existência de normativas como a Lei $n^{\circ} 10.639$, de 2003, que altera a Lei de Diretrizes e Bases da Educação Nacional (LDB) para incluir no currículo oficial da Rede de Ensino a obrigatoriedade da temática História e Cultura Afro-Brasileira, e as Diretrizes Curriculares Nacionais para a Educação das Relações Étnico-Raciais e para o Ensino de História e Cultura AfroBrasileira, de 2004, resultantes da histórica luta do Movimento Negro.

Os títulos de literatura infanto-juvenil com personagens negros continuam muito restritos nos acervos das bibliotecas escolares e, quando presentes, fazse necessário atentar para a maneira como são representados, pois, em pleno século XXI, permanecem manifestações implícitas e explícitas de preconceito e imagens negativas, nas quais o ser ficcional negro é associado à pobreza, visto como alvo de violências e constantemente subordinado ao branco, considerado superior.

Em muitas obras, ao longo do tempo, os sujeitos negros foram identificados por apelidos depreciativos ou sequer receberam um nome. Marcados por estereótipos racistas, foram vinculados a personagens maus, à sujeira e à tragédia, classificados como bandidos, malandros, preguiçosos, serviçais e inseridos num ambiente de pobreza e preconceito racial, o que acabou se refletindo em sala de aula, como podemos perceber no trecho abaixo:

Os alunos destes educadores (da Educação Infantil e do Ensino Fundamental), em grande maioria negros, ou morenos, como se autodenominam, e outros de pele clara, quando das festas realizadas nas escolas, escolhiam os colegas para representar papéis de heróis, príncipes, princesas, fadas, conforme o padrão de beleza branco: pele clara e cabelos lisos, de preferência, louros. Agora, quando se tratava de escolher aqueles que seriam os antagonistas, o Saci Pererê, a bruxa, o representante do mal, indicavam os colegas negros (OLIVEIRA, 2003, p. 20). 


\section{HISTÓRIA}

Dossiê: Ensino de História, História das Mulheres e Desigualdades Sociais no Brasil

Para que a escola se torne um ambiente efetivamente inclusivo muitas mudanças são necessárias. Precisamos descolonizar os currículos, como propôs Nilma Gomes, trazendo propostas que sejam mais condizentes com a realidade sociocultural e que contribuam para o desenvolvimento do indivíduo, ao invés de somente treiná-lo para avaliações (GOMES, 2012).

Como declararam Cordeiro e Pinheiro, devemos mudar nossas práticas, promover uma reeducação para as relações étnico-raciais e valorizar a história e cultura afro-brasileira. Devemos contemplar os saberes, os valores e as necessidades de sujeitos que, até então, foram invisibilizados pelo sistema educacional, ampliando as possibilidades de acesso a materiais pedagógicos que contemplem a pluralidade cultural e fazer com que eles cheguem às salas de aula para que as crianças e jovens negros tenham acesso a conteúdos e histórias que falem sobre suas subjetividades e, assim, se sintam representados e valorizados (CORDEIRO; PINHEIRO, 2018).

Assim, acreditamos que a atividade proposta neste artigo possa contribuir para a introdução dos debates sobre as exclusões de gênero e raça, para que as meninas negras estabeleçam afinidades com nossa heroína, reconhecendose como afrodescendentes, e para reduzir as discriminações com relação às mulheres e à negritude. Essas discussões são fundamentais para que a sociedade brasileira admita seu racismo, pois somente assim seremos capazes de combatê-lo.

\section{Referências}

ADICHIE, Chimamanda. O perigo de uma história única. Por dentro da África, 2013. Disponível em: http://www.pordentrodaafrica.com/cultura/o-perigo-deuma-historia-unica-por-chimamanda-adichie. Acesso em: 10 de maio de 2020.

ARRAES, Jarid. As lendas de Dandara. Porto Alegre: Liro Editora Livre, 2015.

ASANTE, Molefi Kete. Afrocentricidade como Crítica do Paradigma Hegemônico Ocidental: Introdução a uma Ideia. Ensaios Filosóficos.

Tradução. Rio de Janeiro, p. 9-18. volume XIV, dezembro/2016. 


\section{HISTÓRIA}

Dossiê: Ensino de História, História das Mulheres e Desigualdades Sociais no Brasil

AYER, Maurício. Na origem de um feminismo negro. Revista Fórum, 2015.

Disponível em: https://revistaforum.com.br/noticias/na-origem-de-um-

feminismo-negro/. Acesso em: 10 de maio de 2020.

BRANDÃO, Junito de Souza. Mitologia Grega. V. 1. Rio de Janeiro: Ed. Vozes, 2009.

CARNEIRO, Edison. O Quilombo dos Palmares. São Paulo: Companhia Editora Nacional, 1958.

CARNEIRO, Sueli. Apresentação. In.: SCHUMAHER, Schuma; BRAZIL, Érico Vital (org.). Mulheres Negras do Brasil. Rio de Janeiro: Senac Nacional, 2007.

CORDEIRO, Valéria de Freitas; PINHEIRO, Maria de Lourdes. História e Cultura Afro-brasileira em livros didáticos de História do Ensino Fundamental II após a Lei 10.639/2003. Revista Eletrônica História Em Reflexão. v. 12. n. 23. p. 276-296. jan./jun. 2018.

CORREA, Gabriel Siqueira. Conteúdos possíveis a partir da Lei 10.639: as geografias das comunidades remanescentes de quilombo no território brasileiro. Revista Tamoios. Departamento de Geografia da UERJ-FFP. v. 7, n. 1. p. 37-50, 2011.

CRENSHAW, Kimberlé. Documento para o encontro de especialistas em aspectos da discriminação racial relativos ao gênero. Estudos Feministas. Ano 10. p. $171-188.1^{\circ}$ semestre 2002.

DUARTE, Eduardo de Assis. Por um conceito de literatura afro-brasileira. In.: DUARTE, Eduardo de Assis; FONSECA, Maria Nazareth Soares (orgs.).

Literatura e afrodescendência no Brasil: Antologia crítica. Belo Horizonte: Editora UFMG, 2014. v.4.

FARIA, Sheila de Castro. Sinhás pretas, damas mercadoras. Tese (Prof. Titular em História do Brasil - UFF). Niterói, 2004.

FUNARI, Pedro Paulo A. Heterogeneidade e conflito na interpretação do Quilombo dos Palmares. Revista de História Regional. v. 6, n. 1. p. 11-38, 2001.

GOMES, Nilma Lino. Relações Étnico-raciais, educação e descolonização dos currículos. Currículo sem Fronteiras. V. 12, n.1, p.98-109, Jan/Abr 2012.

LOPES, Nei. Enciclopédia brasileira da diáspora africana. São Paulo: Selo Negro, 2004.

LUSSAC, Ricardo Martins Porto; TUBINO, Manoel José Gomes. Capoeira: A história e trajetória de um patrimônio cultural do Brasil. Revista da Educação Física/UEM. Maringá, v.20, n. 1. p. 7-16. Trim. 2009. 


\section{HISTÓRIA}

Dossiê: Ensino de História, História das Mulheres e Desigualdades Sociais no Brasil

LUNZ, Leandro da Silva. Mulher e história: Da invisibilidade à sujeito de

análise. Revista Eletrônica História em Reflexão. Dourados, MS. v. 12. n. 23.

p. 49-67. jan./jun. 2018.

MACUL, Marcus Vinícius Santana. Capoeira: Luta de resistência à violência.

Boletim Interfaces da Psicologia da UFRural. p. 50-74. $2^{\circ}$ Seminário - Ano 2008. Disponível em:

http://www.ufrri.br/seminariopsi/2008/boletim/pdf/Artigo\%20Marcus\%20Macul.p df. Acesso em: 15 de maio de 2020.

MOURA, Clóvis. Os quilombos e a rebelião negra. São Paulo: Brasiliense, 1986.

NASCIMENTO, Elisa Larkin; GÁ, Luiz Carlos. Adinkra, Sabedoria em símbolos africanos. Rio de Janeiro: Ipeafro/Pallas, 2009.

OLIVEIRA, Luiz Fernandes de Oliveira; CANDAU, Vera Maria Ferrão. Pedagogia decolonial e educação antirracista e intercultural no Brasil. Educação em Revista. Belo Horizonte. v.26. n.01. p. 15-40. abr. 2010.

OLIVEIRA, Maria Anória de Jesus. Negros personagens nas narrativas literárias infanto-juvenis brasileiras: 1979-1989. Dissertação (Mestrado em Educação e Contemporaneidade). Departamento de Educação. Universidade do Estado da Bahia - UNEB. Salvador-Bahia, 2003.

FROES, Ricardo. Significados dos nomes próprios africanos, 2009.

Disponível em:https://dicionariosvarios.blogspot.com/2009/06/significado-dosnomes-proprios.html. Acesso em: 29 de maio de 2020.

PORTZ, Renata Moschen. Abrindo Caminho: A mitologia dos orixás na cultura popular brasileira. Trabalho de conclusão de curso (Licenciatura em Letras). Instituto de Letras. Universidade Federal do Rio Grande do Sul UFRS. Porto Alegre, 2011.

PRANDI, Reginaldo. Oxumarê, o Arco-Íris: mais histórias dos deuses africanos que vieram para o Brasil com os escravos. São Paulo: Companhia das Letrinhas, 2004.

RIBEIRO, Djamila. Lugar de fala. São Paulo: Sueli Carneiro; Pólen, 2019.

SILVA, Simone Rezende da; NASCIMENTO, Lisangela Kati do. Negros e territórios quilombolas no Brasil. Cadernos Cedem. v. 3, n 1. p. 23-37, 2012.

SILVA, Alberto da Costa e. A África explicada aos meus filhos. Rio de Janeiro: Agir, 2012. 


\section{HISTÓRIA}

Dossiê: Ensino de História, História das Mulheres e Desigualdades Sociais no Brasil

SILVA, Adriano Viaro da. Quilombo dos Palmares - Historiografia do período colonial. XII Encontro Estadual de História ANPUH/RS. Universidade do Vale do Rio dos Sinos. São Leopoldo, RS. p. 1-13. De 11 a 14 de agosto de 2014. Disponível em: http://www.eeh2014.anpuh-

rs.org.br/resources/anais/30/1405448106 ARQUIVO textoparaaANPUH1.3se mresumo.pdf.Acesso em: 16 de maio de 2020.

SOUZA, Duda Porto de; CARARO, Aryane. Extraordinárias - Mulheres que revolucionaram o Brasil. São Paulo: Seguinte, 2017.

TINOCO, Dandara. Descrita como heroína, Dandara, mulher de Zumbi, tem biografia cercada de incertas. O Globo, 2014. Disponível em:

https://oglobo.globo.com/sociedade/historia/descrita-como-heroina-dandaramulher-de-zumbi-tem-biografia-cercada-de-incertezas-14567996. Acesso em: 10 de maio de 2020.

XAVIER, Giovana. Você pode substituir mulheres negras como objeto de estudo por mulheres negras contando sua própria história. Rio de Janeiro: Malê, 2019. 